\title{
Postmortem Changes in Electrolytes and Adrenal Gland at Different Intervals in Adult Male Rats
}

\author{
Rania Abdel Rahman Elgawish ${ }^{1}$, Heba M. A. Abdelrazek², Mohamed Ghanem \\ ${ }^{1}$ Department of Forensic Medicine and Toxicology, Faculty of Veterinary Medicine, \\ Suez Canal University, Ismailia, Egypt \\ reemshab@gmail.com \\ ${ }^{2}$ Department of Physiology, Faculty of Veterinary Medicine, Suez Canal University, Ismailia, Egypt \\ hebaabdelrazekvet@gmail.com \\ ${ }^{3}$ Faculty of Veterinary Medicine, Suez Canal University, Ismailia, Egypt \\ ghanum77@hotmail.com
}

\begin{abstract}
The importance of determining time of death is crucial to forensic cases. The ability to use electrolytes, ions and adrenal gland changes to determine the postmortem intervals were examined in this study. A total of 9 rats were used, three rats for determining postmortem "zero hour" the remaining 6 rats were divided equally into two groups to investigate postmortem "six hour" and postmortem "twelve hour". For each time interval postmortem, the vitreous humor was gently withdrawn for evaluation of $\mathrm{Na}, \mathrm{Cl}$ and $\mathrm{K}$ levels as well as Ca and P. Part of skeletal and cardiac muscles was taken at postmortem 0, 6, and 12 h for lactate analysis. The left adrenal gland was excised and fixed in $10 \%$ formalin solution and stained with hematoxylin eosin $(H \& E)$ and a special stain for adrenal gland. The volume of the cortex and medulla of the adrenal gland was evaluated. The levels of $\mathrm{Na}$ and $\mathrm{Cl}$ showed non-significant $(P=0.4)$ changes at 0,6 and $12 \mathrm{~h}$. The $\mathrm{K}$ level was increased significantly $(P=0.01)$ in rats at $0 \mathrm{~h}$ compared to $12 \mathrm{~h}$. The Ca was decreased significantly $(P=0.02)$ in rats at $0 \mathrm{~h}$ compared to $12 \mathrm{~h}$. The lactate in skeletal $(P=0.04)$ and cardiac muscles $(P=0.001)$ showed significant increase at $12 \mathrm{~h}$ than that at $0 \mathrm{~h}$. Total volume of the adrenal gland and adrenal cortex has been increased at $12 \mathrm{~h}$, however, significant decrease in medullary volume $(P=0.03)$ was detected at $12 \mathrm{~h}$. Marked expansion of cortex was detected. The cellular outline of the medulla was indistinct. Pyknotic nuclei were observed in several places at $12 \mathrm{~h}$. In conclusion, $K$ and $C a$ in vitreous humors as well as lactate levels in skeletal and cardiac muscle tissues were markedly changed by postmortem time intervals. Histopathological changes and the volume of adrenal gland could be used reliably in determining the postmortem intervals. A more detailed study including large number of rats is planned in the near future.
\end{abstract}

Keywords: Postmortem, rats, electrolytes, adrenal gland

\section{INTRODUCTION}

The importance of determining the time after death is crucial to forensic cases. Postmortem changes include different processes such as body cooling, hypostasis, rigor mortis, metabolite concentrations, enzyme activity and morphological changes $[1,2]$. Most of the chemical methods used for assessment the time after death are based on some parameters, one of the parameter is autolysis, with rupture of cell membranes [3]. There are few scientific approaches based on chemical evaluation that can be used to estimate the postmortem interval (PMI). Changes in blood and other tissues fluid biochemistry are assessed; however considerable inaccuracy has been determined. The most used chemical indicator of the PMI before putrefaction is the potassium content of the vitreous humor [4]. The higher the concentration, the more suitable is the substance for the estimation of the PMI [5].

The adrenal gland is one of the first autolysed tissues in the body. There are studies that describe the relationship between the postmortem interval and autolysis of the myocardium and sublingual gland. However, postmortem interval studies that include the adrenal gland are lacking [6]. The volume of the adrenal gland increased over time after death [6]. The loss of adrenocortical lipids can be detected after a long time [7], and the nuclei of adrenal cells decreased in size, followed by cellular shrinkage [8].

Historically, analysis of postmortem blood was the most extensively studied because blood carries most substances present in a body [4], although vitreous humor is being currently examined to 
determine PMI. This is mainly due to the fact that vitreous humor is well protected and isolated from the blood stream and microbes. Thus, the autolytic changes proceed more slowly compared with blood. This experimental study was designed to determine the postmortem changes in electrolytes and some ions in vitreous humor of adult male albino rats as well as lactate levels in skeletal and cardiac muscles. Moreover, to investigate the relationship between the postmortem interval and autolytic changes in the adrenal gland of male albino rats using special staining method.

\section{MATERIALS AND MeTHODS}

\subsection{Experimental animals and sampling procedures}

Nine, three-month old male albino rats, weighing 185 - $225 \mathrm{~g}$, were fed ad libitum and were kept at Laboratory Animal House of Faculty of Veterinary Medicine, Suez Canal University, Egypt. Rats underwent cervical dislocation. Three of the rats under cervical dislocation were separated for immediate dissection. These rats were used for determining postmortem " $0 \mathrm{~h}$ values" the remaining 6 rats were divided into two groups (3 rats / group) to investigate postmortem " $6 \mathrm{~h}$ values" and postmortem " $12 \mathrm{~h}$ values". The rats were kept at constant temperature $\left(14 \pm 2{ }^{\circ} \mathrm{C}\right)$ throughout the time intervals of the experiment. All the protocols regarding the study were approved by institutional ethical committee and conducted according to the ethical guidelines for the use of animals in laboratory experiments of the Faculty of Veterinary Medicine, Suez Canal University, Egypt.

\subsection{Vitreous humor sampling}

For each time interval postmortem, the vitreous humor was gently withdrawn by syringe, and each sample was placed in a polypropylene tube. The samples were stored at $-18{ }^{\circ} \mathrm{C}$ until evaluation of sodium $(\mathrm{Na})$, chloride $(\mathrm{Cl})$ and potassium $(\mathrm{K})$ electrolytes levels as well as calcium $(\mathrm{Ca})$ and phosphorus (P) ions.

\subsection{Electrolytes and ions levels}

Electrolytes ( $\mathrm{Na}, \mathrm{Cl}$ and $\mathrm{K}$ ) as well as ions ( $\mathrm{Ca}$ and $\mathrm{P}$ ) were analyzed on Roche Cobas 6000 auto analyzer (Roche Diagnostics, Mannheim, Germany) with the original reagents (Roche Diagnostics GmbH D- 68298 Mannheim, Germany) at the Laboratory of Clinical Pathology, Faculty of Medicine, Suez Canal University.

\subsection{Skeletal and cardiac muscles tissue sampling}

At each time interval $(0,6$ and $12 \mathrm{~h})$ postmortem, the rats that were set aside following cervical dislocation underwent immediate dissection. The muscle of the right thigh and the heart muscle were put in to $10 \mathrm{ml}$ polypropylene tubes, and kept at $-20^{\circ} \mathrm{C}$ until lactate levels were analyzed.

\subsection{Lactate levels in muscles}

At the time of sample preparations for lactate analysis, $0.5 \mathrm{~g}$ of the skeletal and cardiac muscles was taken at 0,6 , and $12 \mathrm{~h}$ following cervical dislocation. Samples were put on $2.5 \mathrm{ml}$ of phosphate buffer saline ( $\mathrm{pH} 7.2)$ to prepare tissue homogenate. The sample were centrifuged at $3000 \mathrm{rpm}$ for $15 \mathrm{~min}$. and sent for lactate measurements analysis on Roche Cobas 6000 auto analyzer (Roche Diagnostics, Mannheim, Germany) at the Laboratory of Clinical Pathology, Faculty of Medicine, Suez Canal University.

\subsection{Histopathology of adrenal glands}

The left adrenal gland was excised and fixed in $10 \%$ formalin solution and then embedded in paraffin according to standard procedures. Ten to fifteen sections of $30 \mu \mathrm{m}$ thick were obtained from each left adrenal gland and stained with hematoxylin eosin (H\&E). Other sections were stained with DiffQuick stain (Sysmex, Kobe, Japan) as a special stain of adrenal gland medulla. The volume of the cortex and medulla of the adrenal gland was evaluated using Image Analysis software (Visual measure 32 for Windows, Version 1.7, Rise Corporation, Japan) at 0, 6, and $12 \mathrm{~h}$ postmortem.

\subsection{Statistical analysis}

All values were expressed as mean \pm standard error of the mean. Comparisons of electrolytes, ions, lactate level and relative weight of the adrenal gland obtained at 0,6 and $12 \mathrm{~h}$ postmortem were performed with one way analysis of variance (ANOVA). Inter-group comparisons were made with Tukey's multiple comparison tests. The volume of the cortex, medulla and total volume of the adrenal gland were evaluated with Kruskal-Wallis test. When a significant difference was detected, the Dunns test was used to identify the source of the difference. A $P$ value of $<0.05$ was considered to indicate 
significance. All the analysis was done using GraphPad Prism (Version 5.01, GraphPad Software, San Diego, USA).

\section{RESULTS}

\subsection{Electrolytes and ions levels in vitreous humor}

The levels of $\mathrm{Na}$ and $\mathrm{Cl}$ showed non-significant $(\mathrm{P}=0.4)$ difference at 0,6 and $12 \mathrm{~h}$ postmortem, in spite of the slight decrease in the $\mathrm{Na}$ and $\mathrm{Cl}$ values by the time interval from 0 to $12 \mathrm{~h}$ after death of the rats. The $\mathrm{K}$ levels was increased significantly $(\mathrm{P}=0.01)$ in rats at $0 \mathrm{~h}$ compared to the levels at $12 \mathrm{~h}$ postmortem. The Ca levels was decreased significantly $(\mathrm{P}=0.02)$ in rats at $0 \mathrm{~h}$ compared to that levels at $12 \mathrm{~h}$ postmortem. In contrary, the $\mathrm{P}$ values was not significantly $(\mathrm{P}=0.2)$ changed in rats at 0,6 and $12 \mathrm{~h}$ postmortem (Table 1).

\subsection{Lactate levels in muscles}

The lactate levels in skeletal muscle of the rats at $12 \mathrm{~h}$ postmortem showed significant $(\mathrm{P}=0.04)$ increase than that levels at $0 \mathrm{~h}$. Moreover, the lactate levels in cardiac muscle was significantly $(\mathrm{P}=0.001)$ increased at 6 and $12 \mathrm{~h}$ compared to $0 \mathrm{~h}$ postmortem (Table 1).

Table 1. Levels of electrolytes ( $\mathrm{Na}, \mathrm{K}$ and $\mathrm{Cl})$ and ions $(\mathrm{Ca}$ and $\mathrm{P})$ in vitreous humor as well as lactate levels in skeletal and cardiac muscles at different postmortem times in male rats. Different superscript at the same row indicate significance $(P<0.05)$

\begin{tabular}{|c|c|c|c|c|}
\hline Parameters & $\mathbf{0 ~ h}$ & $\mathbf{6 ~ h}$ & $\mathbf{1 2} \mathbf{~ h}$ & $\boldsymbol{P}$ \\
\hline $\mathbf{N a}(\mathbf{m m o l} / \mathbf{L})$ & $150 \pm 32.5$ & $130 \pm 5.8$ & $110.0 \pm 5.0$ & 0.4 \\
\hline $\mathbf{K}(\mathbf{m m o l} / \mathbf{L})$ & $44.5 \pm 0.3^{\mathrm{a}}$ & $53.5 \pm 1.8^{\mathrm{ab}}$ & $62.0 \pm 4.3^{\mathrm{b}}$ & 0.01 \\
\hline $\mathbf{C l}(\mathbf{m m o l} / \mathbf{L})$ & $110.5 \pm 19.8$ & $101.0 \pm 3.2$ & $88.3 \pm 4.4$ & 0.4 \\
\hline $\mathbf{C a}(\mathbf{m g} / \mathbf{d l})$ & $7.3 \pm 1.2^{\mathrm{a}}$ & $5.5 \pm 0.1^{\mathrm{ab}}$ & $3.5 \pm 0.3^{\mathrm{b}}$ & 0.02 \\
\hline $\mathbf{P}(\mathbf{m g} / \mathbf{d l})$ & $95.0 \pm 18.6$ & $70.7 \pm 5.2$ & $61.2 \pm 2.9$ & 0.2 \\
\hline $\begin{array}{c}\text { Skeletal lactate } \\
(\mathbf{m g} / \mathbf{d l})\end{array}$ & $51.3 \pm 2.2^{\mathrm{a}}$ & $80.3 \pm 7.5^{\mathrm{ab}}$ & $101.7 \pm 16.7^{\mathrm{b}}$ & 0.04 \\
\hline $\begin{array}{c}\text { Cardiac lactate } \\
(\mathbf{m g} / \mathbf{d l})\end{array}$ & $12.3 \pm 1.5^{\mathrm{a}}$ & $32.7 \pm 1.5^{\mathrm{b}}$ & $54.7 \pm 2.6^{\mathrm{c}}$ & 0.001 \\
\hline
\end{tabular}

\subsection{Relative weight and volume of adrenal gland at different time interval}

The relative weight of the left adrenal gland $(0.013 \pm 0.001) \mathrm{g}$ at $12 \mathrm{~h}$ was significantly higher $(\mathrm{P}=$ $0.04)$, than that at $(0.007 \pm 0.001) \mathrm{g}$. Total volume of the adrenal gland has been increased from $(3.98 \pm 0.91) \mathrm{mm}^{3}$ at $0 \mathrm{~h}$ to $(6.21 \pm 0.44) \mathrm{mm}^{3}$ at $12 \mathrm{~h}$ postmortem without reaching a significant difference $(\mathrm{P}=0.14)$. The cortex of the adrenal gland increased from $(3.79 \pm 0.88) \mathrm{mm}^{3}$ at $0 \mathrm{~h}$ to $(4.96 \pm 0.73) \mathrm{mm}^{3}$ at $12 \mathrm{~h}$ postmortem without reaching a significant difference $(\mathrm{P}=0.53)$, however, a significant decrease in medullar volume $(\mathrm{P}=0.03)$ was detected between $0 \mathrm{~h}(0.80 \pm 0.16) \mathrm{mm}^{3}$ and 12 h $(0.43 \pm 0.01) \mathrm{mm}^{3}$ (Fig. 1).

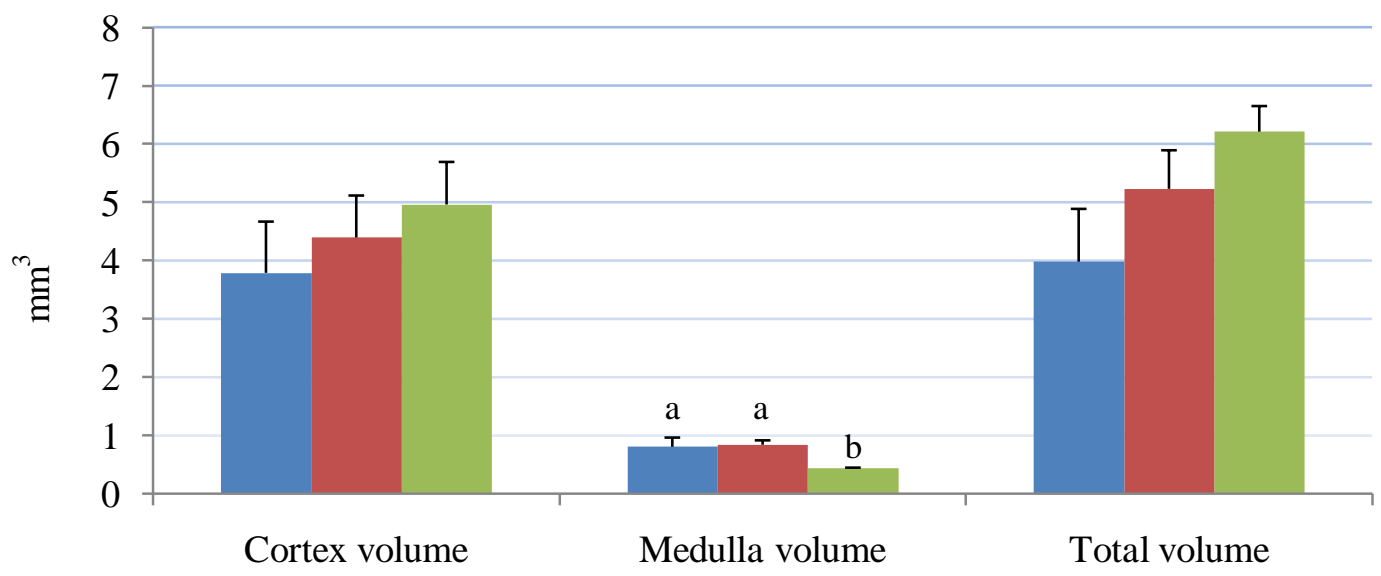

$$
\begin{gathered}
\text { Postmortem hours } \\
\square 0 \mathrm{~h} \quad \square 6 \mathrm{~h} \quad \square 12 \mathrm{~h}
\end{gathered}
$$

Fig.1. Cortex, medulla and total volume of adrenal gland at 0, 6 and $12 \mathrm{~h}$ postmortem. A P value of $<0.05$ was considered to indicate significance 


\subsection{Histopathology of adrenal gland}

The adrenal gland at $O h$ had normal maintained architecture with well differentiated cortex and medulla. The cortex showed normal histological structure of the three zones. Zona granulosa (ZG) showed normal epithelium with intact basement membrane and most of the nuclei were completely hyperchromatic with rarely pyknotic or vesicular nuclei. Zona fasciculata (ZF) and zona reticularis (ZR) showed normal non dilated sinusoids with prominent endothelial cells. Most cells had hyperchromatic and eosinophilc abundant cytoplasm. Medulla (M) was distinct and well differentiated from cortex; most of the nuclei were completely hyperchromatic with normal intact blood vessels. At $6 \mathrm{~h}$ postmortem, architecture was slightly maintained and the cortex could be differentiated from the medulla. The cortex was expanded in expense of medulla, while at $12 \mathrm{~h}$ a marked expansion was observed. Cellular outline of ZG, ZF and ZR was not clear and cytoplasm showed vacuolation. Most of the nuclei were completely pyknotic and vesicular nuclei were seen at 6 and $12 \mathrm{~h}$. The sinusoids showed moderate to marked dilatation with few prominent endothelial cells at $12 \mathrm{~h}$. The cellular outline of the medulla was indistinct. Pyknotic nuclei were observed in several places at $12 h$ (Fig. 2-5).
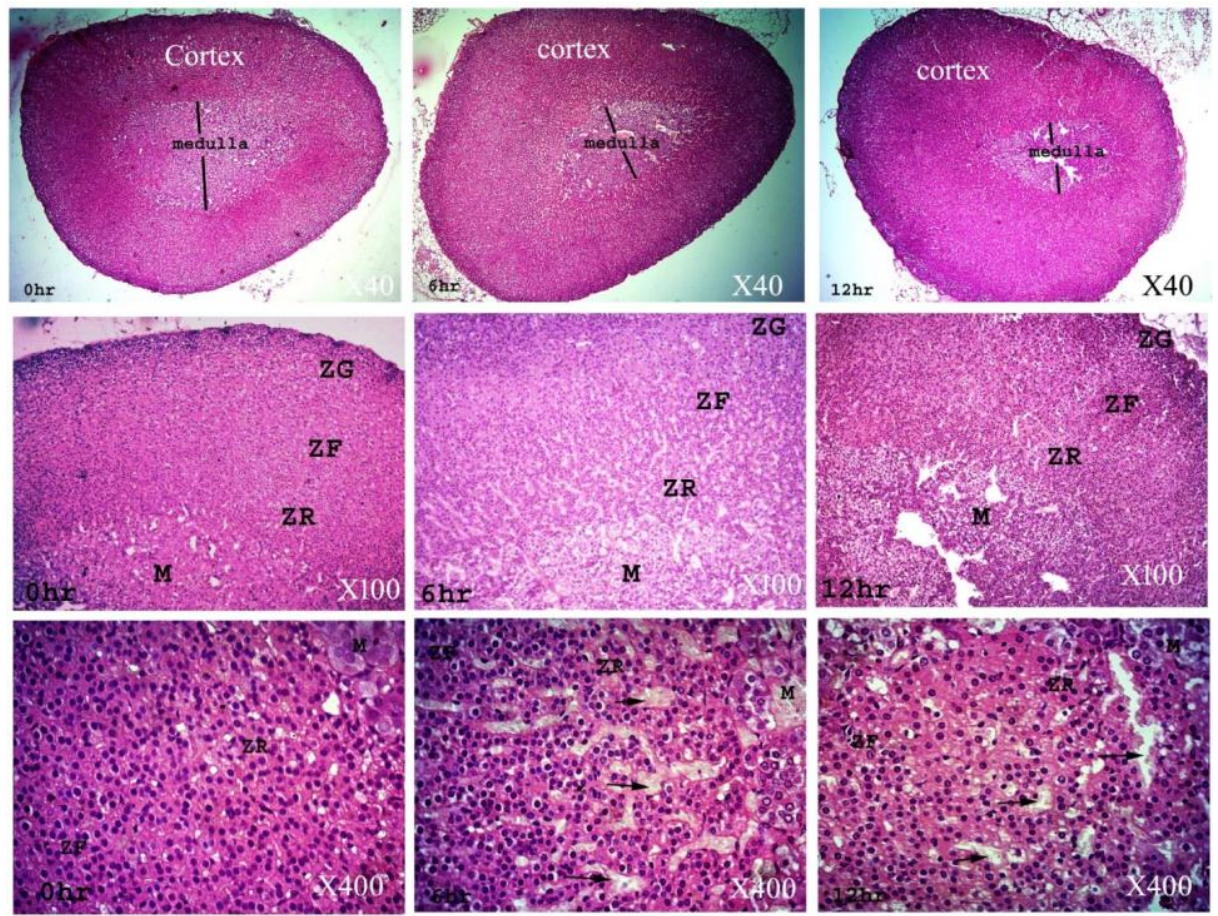

Fig. 2. Adrenal gland ( $H \& E$ stain). At 0 h, architecture was maintained. Cortex was well differentiated from the medulla. At 6 and $12 \mathrm{~h}$, cortex expanded in expense to medulla. At 6 and $12 \mathrm{~h}$ sinusoids were dilated (arrows at $X$ 400)
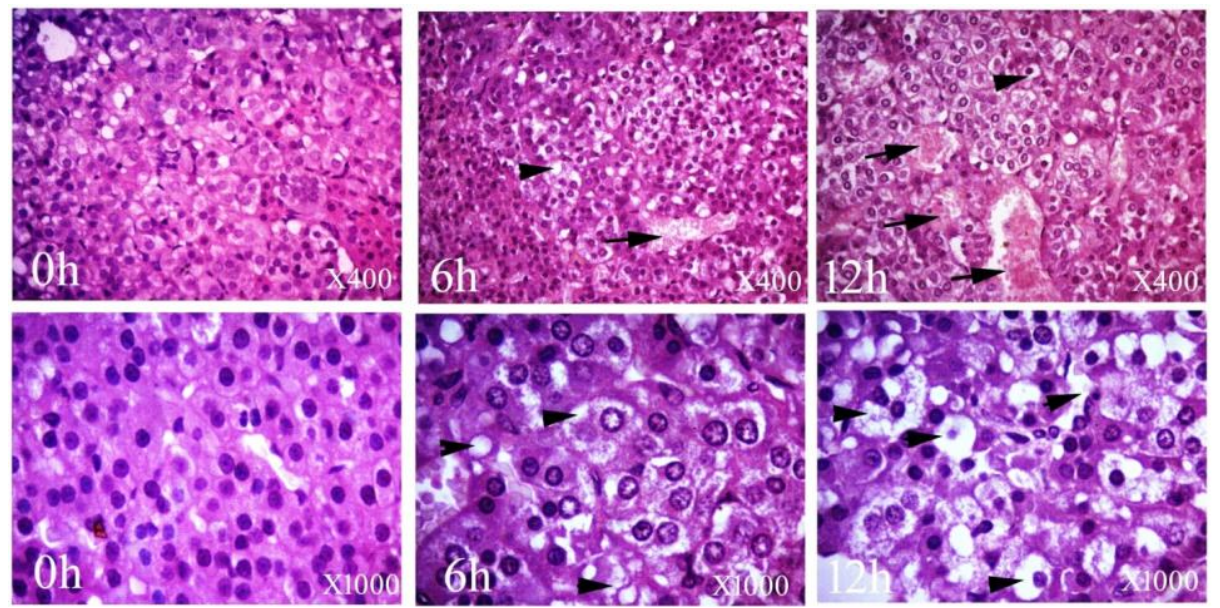

Fig. 3. Adrenal gland ( $H \& E$ stain, $X 400$ and $X$ 1000). At 0 h, medulla showed distinct cellular outlines with hyperchromatic nuclei. At 6 and 12 h, blood vessels were dilated (arrows), cytoplasm was vacuolated (arrow heads) and most nuclei were vesicular and pyknotic 

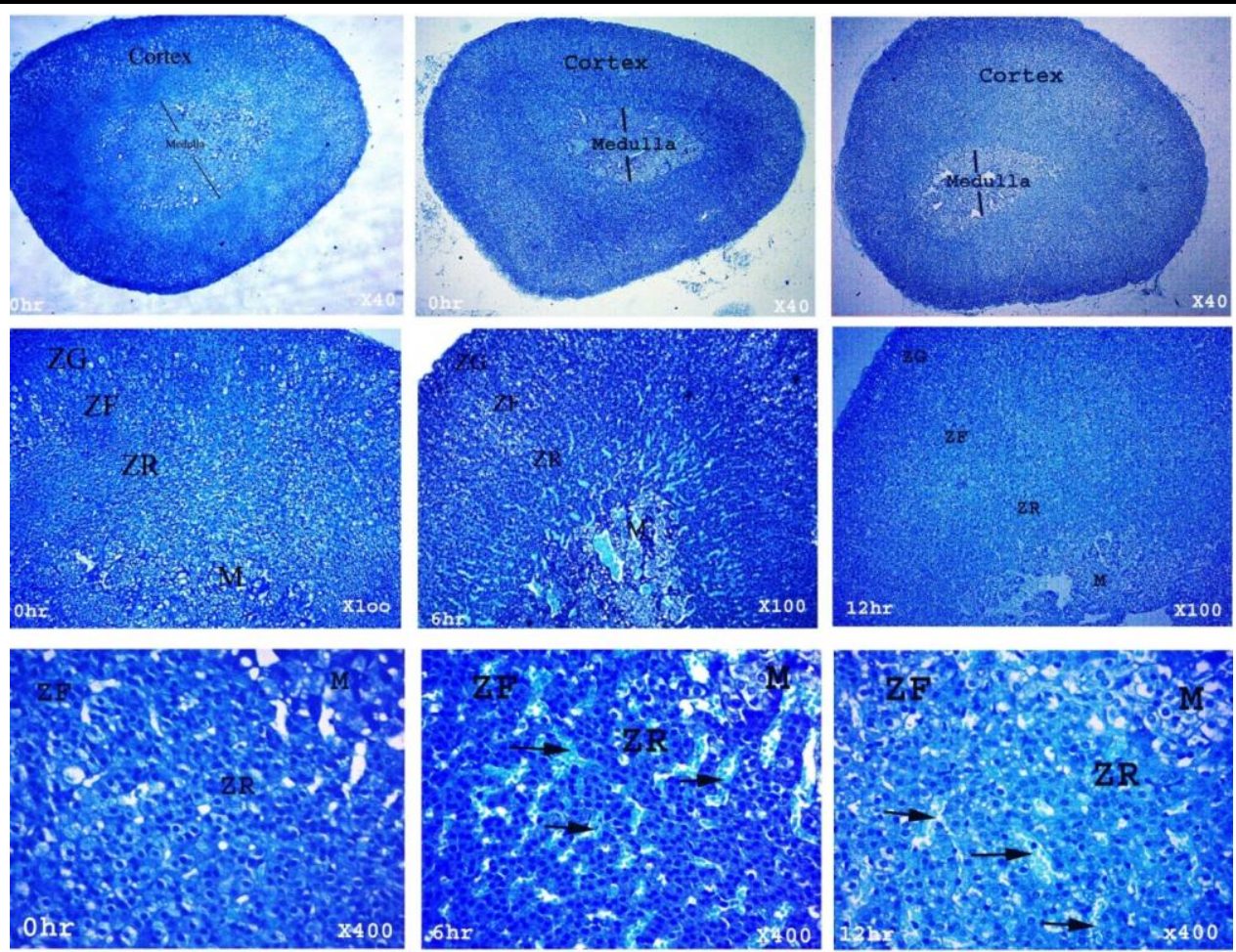

Fig. 4. Adrenal gland (Diff-Quik stain). At 0 h, architecture was maintained. Cortex was well differentiated from the medulla. At 6 and $12 \mathrm{~h}$, cortex expanded in expense to medulla. At 6 and $12 \mathrm{~h}$ sinusoids were dilated (arrows $X$ 400)

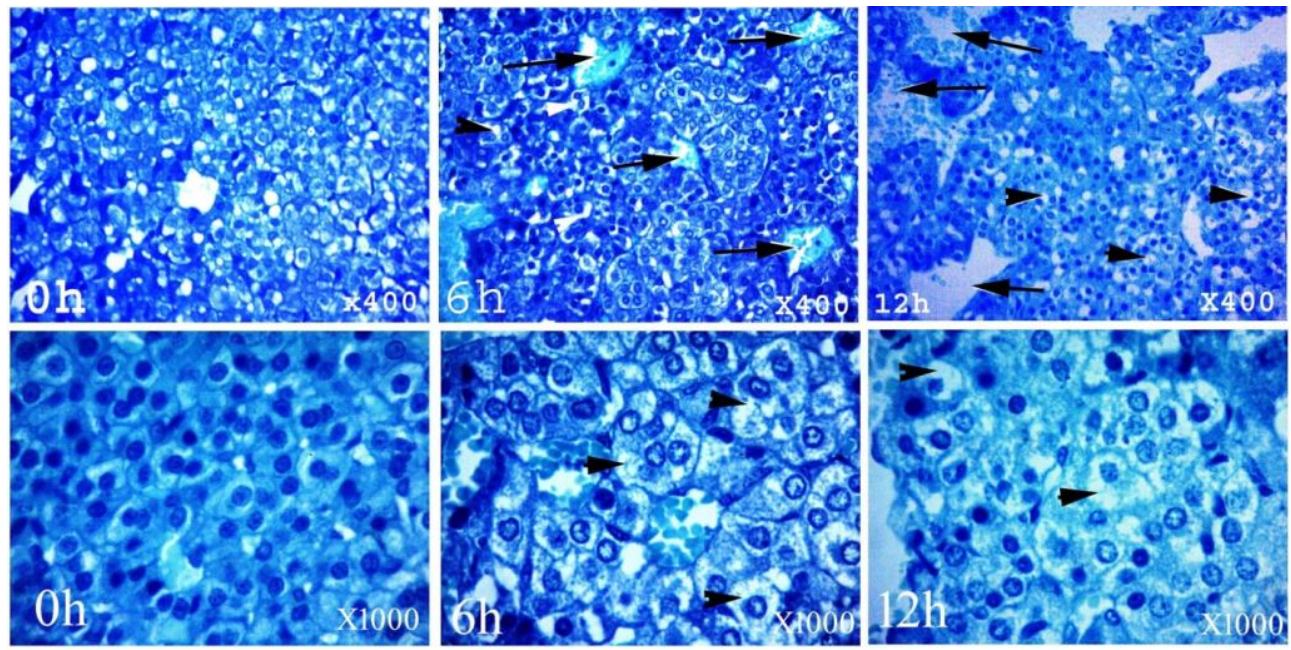

Fig. 5. Adrenal gland (Diff-Quik stain, $X 400$ and X 1000). At 0 h, medulla showed distinct cellular outlines with hyperchromatic nuclei. At 6 and 12 h, blood vessels were dilated (arrows), cytoplasm was vacuolated (arrow heads) and most nuclei were vesicular and pyknotic

\section{DisCUSSION}

Biochemical profiles from body fluids taken after death can provide useful information regarding cause of death and have the potential to provide PMI estimations if suitable postmortem biochemical markers are identified [9]. In the present study, the levels of $\mathrm{Na}$ and $\mathrm{Cl}$ showed non-significant $(\mathrm{P}=0.4)$ difference at 0,6 and $12 \mathrm{~h}$ postmortem, in spite of the slight decrease in the $\mathrm{Na}$ and $\mathrm{Cl}$ values by the time interval from 0 to $12 \mathrm{~h}$. Concentrations of sodium and chloride decreased by $1 \mathrm{mmol} / \mathrm{L}$ per hour for the first 3-52 hours postmortem in serum [4, 10-13]. These two markers are not reliable enough to be used as a PMI indicator; they are now measured only from the vitreous humor, rather than serum $[4,10]$. In the current experiment, $\mathrm{K}$ level was increased significantly $(\mathrm{P}=0.01)$ in rats at 0 $\mathrm{h}$ compared to the levels at $12 \mathrm{~h}$ postmortem. Serum K levels rapidly increased over the first 1-2 $\mathrm{h}$ after death $[11,14,15]$. As with $\mathrm{Na}$ and $\mathrm{Cl}, \mathrm{K}$ is measured in the vitreous humor. This is because it has been repeatedly shown to rise rapidly in the first 6-12 h after death and then linearly after $24 \mathrm{~h}$ [4, $10,13,15]$. In general the discrepancy in the results of postmortem electrolytes values among 
researchers might be due to temperature, sampling techniques, differences between each eye as well as the age of the individual [16].

In the present study, Ca levels was decreased significantly $(\mathrm{P}=0.02)$ in rats at $0 \mathrm{~h}$ compared to that levels at $12 \mathrm{~h}$ postmortem. In contrary to our study, Jetter [14] reported that the plasma calcium concentration was relatively stable from 12-24 h postmortem. Hodgkinson and Hambleton [17] found that plasma calcium concentration increased rapidly within an hour postmortem from $4 \mathrm{mmol} / \mathrm{L}$ to reach $9.4 \mathrm{mmol} / \mathrm{L}$ after $5 \mathrm{~h}$ before decreasing back to antemortem levels by $11 \mathrm{~h}$. Fekete and Brunsdon [18] found a wide range of serum calcium concentrations within 2-36 h postmortem. All of these researchers used different methods to analyze serum calcium concentrations and that may explain why the findings are so variable, indicating that blood calcium levels are not a reliable indicator of PMI. In the current work, $P$ values was not significantly $(P=0.2)$ changed in rats at 0,6 and $12 \mathrm{~h}$ postmortem. In contrary to our study, postmortem increase was observed for organic and inorganic phosphorus [14]. Inorganic phosphate was reported to be present at antemortem concentrations of $0.6-0.9 \mathrm{mmol} / \mathrm{L}$ and rises within one hour postmortem to reach concentrations of $6.6 \mathrm{mmol} / \mathrm{L}$ by $18 \mathrm{~h}$ after death [14].

Autolysis starts approximately 4 min after death. As cells of the body are deprived of oxygen, carbon dioxide in the blood increases, $\mathrm{pH}$ decreases, and wastes accumulate, which poison the cells. In this study, skeletal muscle tissue was selected for analysis because the skeletal muscle tissue autolytic changes and putrefaction proceed slower compared to body fluids and organs [3]. In the present work, the lactate levels in skeletal muscle at $12 \mathrm{~h}$ postmortem showed significant $(\mathrm{P}=0.04)$ increase than that levels at $0 \mathrm{~h}$. Moreover, the lactate levels in cardiac muscle was significantly $(\mathrm{P}=0.001)$ increased at 6 and $12 \mathrm{~h}$ compared to that at $0 \mathrm{~h}$ postmortem. Postmortem serum lactate in human heart blood has been increased in the blood 20 folds one hour after death and rose 50-70 times higher than antemortem levels by $24 \mathrm{~h}$ [14]. Lactate has also been measured postmortem in cerebrospinal fluid [13], vitreous humor [19]. It has been suggested that lactate concentrations in the bloodstream postmortem may be affected by lactate diffusion from muscular tissues and because of blood glycolysis in the vessels, which would make lactic acid an unsatisfactory marker for PMI [13]. However, further research is required to determine if lactate is a possible marker for estimation of PMI.

In this study, the relative weight of the adrenal gland has been increased at $12 \mathrm{~h}$ postmortem. Nery et al. [20] determined a $34.3 \%$ increase in the glandular mass of the sublingual gland from 0 to $24 \mathrm{~h}$ and reported that this increase is related to transition of liquids originating from the surrounding tissues. In the present study, total volume of the adrenal gland as well as adrenal cortex has been increased, however, a significant decrease in medullary volume $(\mathrm{P}=0.03)$ was detected at $12 \mathrm{~h}$. Marked expansion of cortex was detected. The cellular outline of the medulla was indistinct. Pyknotic nuclei were observed in several places at $12 \mathrm{~h}$. In accordance to our findings, Kurtulus et al. [6] observed that an enlargement of the total cell size of adrenal gland due to widespread intracytoplasmic vacuolar degenerative change as well as nuclear changes, such as karyolysis, pyknosis and karyorrhexis. The first symptom of the cellular damage is mostly cellular swelling, which is known as "hydropic change" or "vacuolar degeneration". Additionally, Kurtulus et al. [6] observed a substantial amount of edema in the intercellular space of both adrenal cortex and adrenal medulla. Additionally, in the current study, significant decrease in the medulla was observed in the medulla volume in parallel to the time elapsed after death. Alejandro and Strafuss [8] previously reported decrease in the adrenal gland medullar cell nuclei sizes with pyknosis, cytoplasmic vacuolization, cellular shrinkage, karyolysis and cell dissociation in the postmortem period. In conclusion, $\mathrm{K}$ and $\mathrm{Ca}$ in vitreous humor and lactate levels in skeletal and cardiac muscles were changed by postmortem time intervals. Histopathological changes and the volume of adrenal gland could be used reliably in determining the postmortem intervals. A more detailed study including large number of rats is planned in the near future.

\section{ACKNOWLEDGEMENT}

The authors wish to thank Prof. Dr. Amina Dosuky and Dr. Doaa Hosny at Faculty of Veterinary Medicine, Suez Canal University for their useful cooperation during the study.

\section{Conflict of Interests}

All authors state that there is no conflict of interest with the work done in this study. 


\section{REFERENCES}

[1] Knight B., Forensic Pathology. $2^{\text {nd }}$ ed. London, Arnold, pp. 79-80 (1996).

[2] Henssge C., Madea B., Estimation of the time since death. Forensic Sci Int, 165, pp. 182-184 (2007).

[3] Dogan K.H., Gunaydin G., Demirci S., Koc S., Postmortem changes in element levels in rat skeletal muscle tissue. Turkiye Klinikleri J Med Sci, 30, pp. 1332-1338 (2010).

[4] Coe J.I., Postmortem chemistry update. Emphasis on forensic application. Am J Forensic Med Path, 14, pp. 91-117 (1993).

[5] Madea B., Is there recent progress in the estimation of the postmortem interval by means of thanatochemistry? Forensic Sci Int, 151, pp. 139-49 (2005).

[6] Kurtulus A., Acar K., Sorkun H., Kelten C., Boz B., The relationship between adrenal gland morphometric changes and postmortem interval in rats: A stereological study. Legal Med, 14, pp. 214-218 (2012).

[7] Reinhard B.D., Forensic histopathology: fundamentals and perspectives, $1^{\text {st }}$ edn. Springer, Berlin (2012).

[8] Alejandro V.S., Strafuss A.C., Microscopic postmortem changes in adrenal glands of the domestic fowl. Avian Dis, 28, pp. 374-85 (1984).

[9] Lundquist F., Methods of forensic science. London, New York: Interscience Publishers (1963).

[10] Spitz W.U., ed. Spitz and Fisher's medicolegal investigation of death. Guidelines for the application of pathology to crime investigation. $4^{\text {th }}$ ed. Illinois: Charles Thomas Publisher (2006).

[11] Coe J.I., Postmortem chemistries on blood with particular reference to urea-nitrogen, electrolytes and bilirubin. J Forensic Sci, 19, pp. 33-42 (1974).

[12] Singh D., Prashad R., Parkash C., Bansal Y.S., Sharma S.K., Pandey A.N., Linearization of the relationship between serum sodium, potassium concentration, their ratio and time since death in Chandigarh zone of north-west India. Forensic Sci Int, 130, pp. 1-7 (2002).

[13] Schleyer F., Determination of the time of death in the early postmortem interval. Methods Forensic Sci, 2, pp. 253-293 (1963).

[14] Jetter W., Postmortem biochemical changes. J Forensic Sci, 4, pp. 330-341 (1959).

[15] Coe J.I., Vitreous potassium as a measure of the postmortem interval: an historical review and critical evaluation. Forensic Sci Int, 42, pp. 201-213 (1989).

[16] Madea B., Henssge C., Hönig W., Gerbracht A., References for determining the time of death by potassium in vitreous humor. Forensic Sci Int, 40, pp. 231-243 (1989).

[17] Hodgkinson A., Hambleton J., Elevation of serum calcium concentration and changes in other blood parameters after death. J Surg Res, 9, pp. 567-574 (1969).

[18] Fekete J.F., Brunsdon D.F.V., The use of routine laboratory tests in postmortem examinations. Can Soc Forensic Sci J, 7, pp. 238-254 (1974).

[19] Jaffe F.A., Chemical postmortem changes in the intraocular fluid. J Forensic Sci, 7, pp. 231-237 (1962).

[20] Nery L.R., Moreira C.R., Cestari T.M., Taga R., Damante J.H., Postmortem acinar autolysis in rat sublingual gland: a morphometric study. J Appl Oral Sci, 18, pp. 509-514 (2010). 


\section{AUTHORS' BIOGRAPHY}

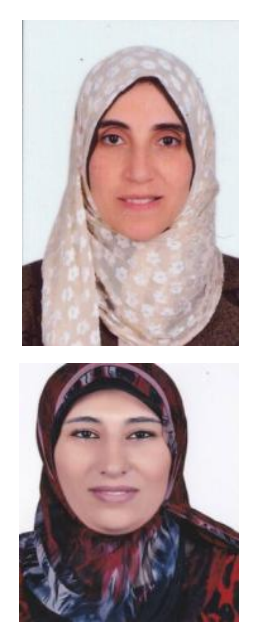

Dr. Rania Abdel Rahman Elgawish, is a lecturer at Department of Forensic Medicine and Toxicology, Faculty of Veterinary Medicine, Suez Canal University, Ismailia, Egypt. She is doing research on the toxic substances affecting the immune and reproductive systems of different animals as well as the postmortem changes in laboratory animals.

Dr. Heba Abdelrazek, is a lecturer at Department of Physiology, Faculty of Veterinary Medicine, Suez Canal University, Ismailia, Egypt. She is working on the effects of different substances on physiological mechanisms inside the body of the animals.

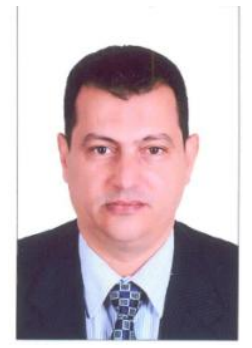

Dr. Mohamed Ghanem, is a professor of Theriogenology, Faculty of Veterinary Medicine, Suez Canal University, Ismailia, Egypt. He is working in the molecular mechanisms related to reproduction in different species. 